\title{
Tracking Changes in Yellowstone's Restless Volcanic System
}

The world-famous Yellowstone
geysers and hot springs are
fueled by heat released from an
enormous reservoir of magma
(partially molten rock beneath
the ground). Since the 1970's,
scientists have tracked rapid
uplift and subsidence of the
ground and significant changes
in hydrothermal (hot water)
features and earthquake activity.
In 2001, the Yellowstone Volcano
Observatory was created by the
U.S. Geological Survey (USGS),
the University of Utah, and
Yellowstone National Park to
strengthen scientists' ability to
track activity that could result in
hazardous seismic, hydrothermal,
or volcanic events in the region.

No actual volcanic eruption has occurred in the Yellowstone National Park region of Wyoming, Montana, and Idaho since a lava flow poured out about 70,000 years ago. However, the area's many geysers and hot springs indicate that the underlying volcanic system remains active. In the early 1970's, Earth scientists found evidence that this system was more active than even these spectacular hydrothermal (hot water) features had suggested.

One important clue was found along the south shore of Yellowstone Lake, where trees were dying because their trunks were partly below water and a boat dock had become completely submerged. At the same time, the water level at the lake's outlet on its north side appeared little changed.

Scientists reasoned that these observations could be explained by southward tilt of the area around Yellowstone Lake, including the lake basin itself. If the entire area was being pushed up, perhaps the ground at the north end of the lake was rising more than the south end, like a giant bathtub lifted at one end. In

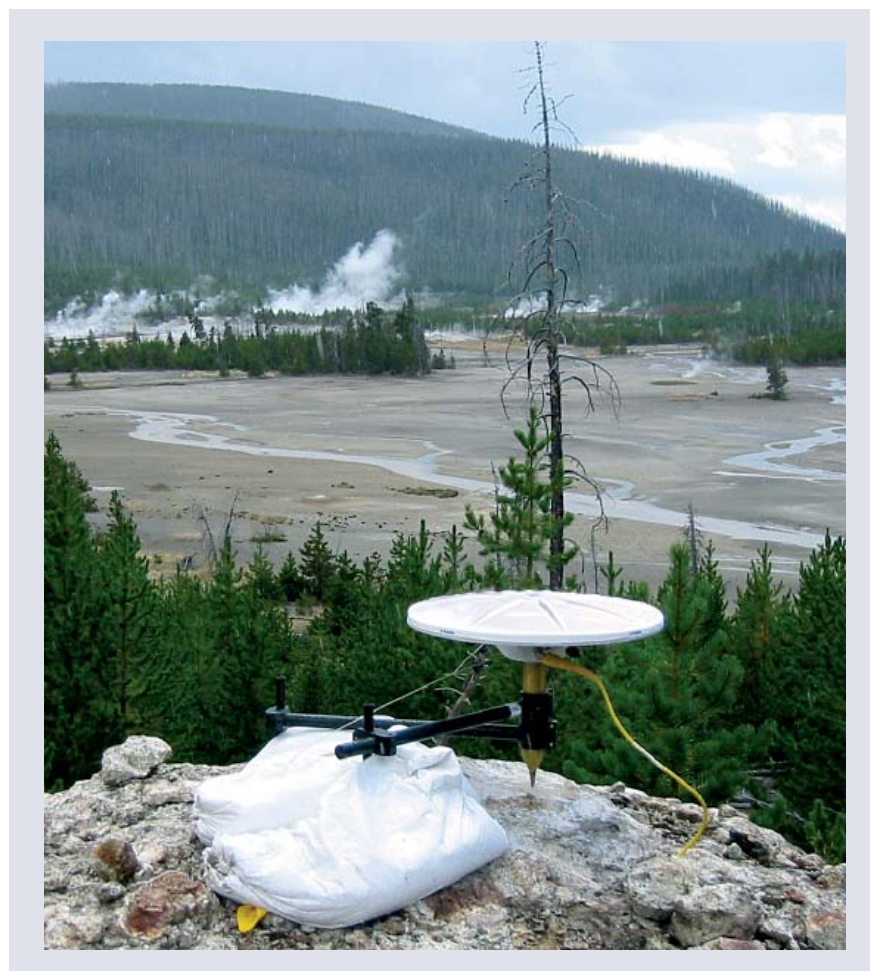

In the 1970s, a resurvey of benchmarks discovered the unprecedented uplift of the Yellowstone Caldera of more than 28 inches $(72 \mathrm{~cm})$ over five decades. More recently, new and revolutionary satellite-based methods for tracking the Earth's shifting ground motions have enabled University of Utah, U.S. Geological Survey, and other scientists to assemble a more precise and detailed picture of Yellowstone's ground movements. Global Positioning System (GPS) stations like this one in the Norris Geyser Basin can detect changes in elevation and horizontal shifts of 1 inch or less per year, helping scientists understand the processes that drive Yellowstone's active volcanic and earthquake systems. (Photo courtesy of Christine Puskas, University of Utah.)

this way, the water level of Yellowstone Lake would appear to rise at the south end.

To test this idea, in 1975-77 scientists from the University of Utah and the U.S. Geological Survey (USGS) resurveyed a series of benchmarks along roads throughout Yellowstone National Park. These benchmarks were originally installed and their elevations and locations precisely determined in 1923. The results of the resurvey showed dramatically that the central part of the park had indeed risen. The greatest uplift appeared to be in the area of Le Hardy Rapids on the Yellowstone River, a few miles downstream from the lake's outlet. There the ground had risen 28.5 inches (72 cm) since 1923, raising the nearby north end of Yellowstone Lake much more than the south end. Scientists then focused their attention on what could be causing the ground to rise and whether the uplift was still going on.

Yellowstone Caldera and its resurgent domes

The 1975-77 survey showed that the area of recent uplift was located within the Yel- lowstone Caldera, a shallow, oval depression, 53 miles long and 28 miles across ( 85 by 45 $\mathrm{km}$ ), in the middle of the park. This caldera was formed 640,000 years ago during the most recent of Yellowstone's great volcanic eruptions. In that eruption, 240 cubic miles $\left(1,000 \mathrm{~km}^{3}\right)$ of molten rock (magma) was blasted into the atmosphere and scattered on the Earth's surface-more than 1,000 times the volume erupted at Mount St. Helens in 1980 ! The ground then collapsed into the partly emptied magma reservoir, forming an enormous craterlike depression.

Later eruptions of many large lava flows, some as thick as 400 feet $(120 \mathrm{~m})$, buried the original caldera floor and most of the caldera walls. Mount Washburn, a prominent landmark in the park, is a section of the caldera rim that escaped burial. The most recent series of eruptions at Yellowstone, 160,000 to 70,000 years ago, covered much of the caldera floor with more than 20 thick lava flows, including the Elephant Back flow, which can be seen west of Fishing Bridge. 


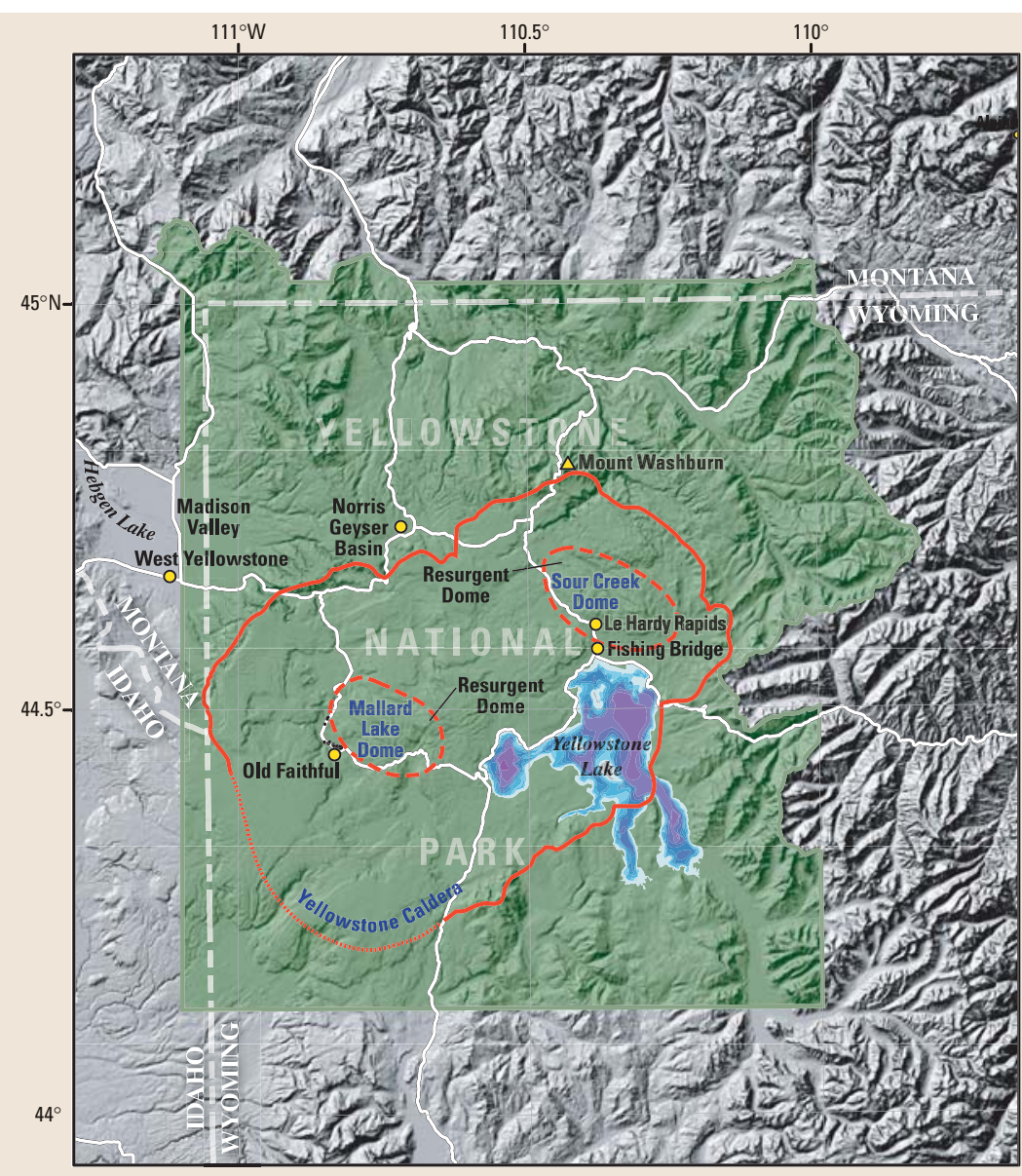

The region of Yellowstone National Park in Wyoming, Montana, and Idaho is famous for its spectacular geysers and extensive hot springs, indications that an underlying volcanic system remains active. The central part of the park is occupied by the great, partly filled depression of the Yellowstone Caldera, formed in a giant volcanic eruption 640,000 years ago that blasted 240 cubic miles $\left(1,000 \mathrm{~km}^{3}\right)$ of molten rock (magma) into the atmosphere-more than 1,000 times the volume erupted at Mount St. Helens in 1980. Later eruptions largely filled the caldera and pushed up two resurgent domes within it-the Sour Creek and Mallard Lake Domes. No actual volcanic eruption has occurred in the Yellowstone region for about 70,000 years. However, since the 1970's, scientists have detected significant changes in this remarkable volcanic and hydrothermal (hot water) system, including rapid ground uplift and subsidence and bursts of earthquake activity.

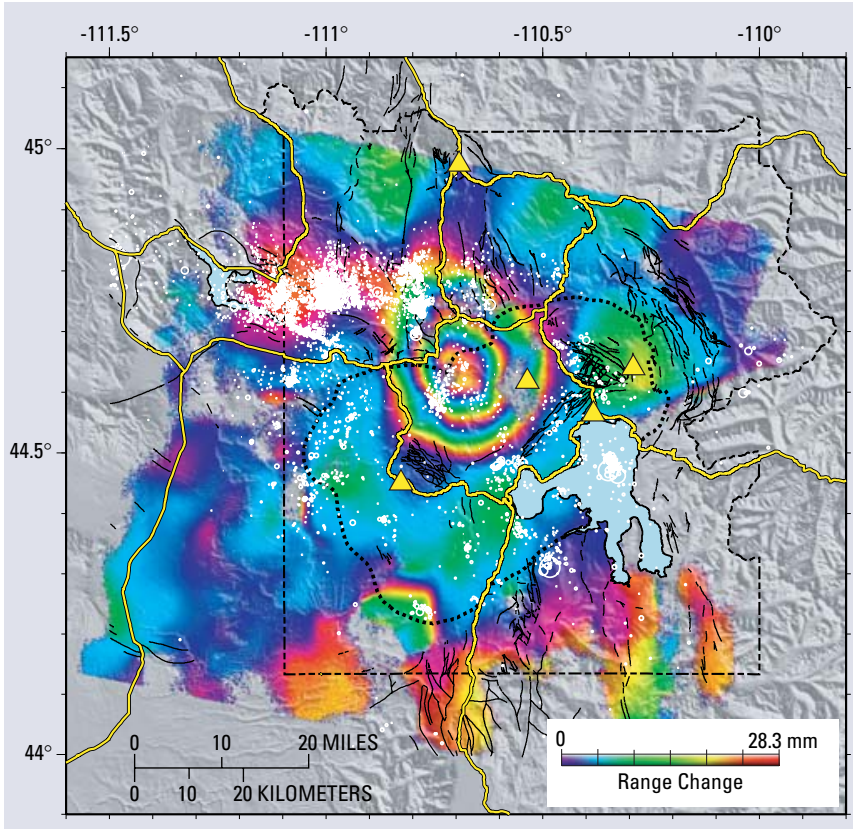

A new satellite-based technique known as Interferomet ric Synthetic Aperture Radar (InSAR) allows direct and precise measurement of the vertical changes in ground level. This InSAR image of the area around the Yellowstone Caldera (dotted line) shows vertical changes during the 4-year period 1996-2000. The ringed pattern centered northwest of Yellowstone Lake is a prominent area of dome-shaped uplift. Each complete cycle of colors in the color bands represents a little more than one inch $(28.3$ $\mathrm{mm}$ ) of vertical change. Yellow triangles are continuous GPS stations; white dots are locations of earthquakes in the period 1996-2000.
The uplift detected in the 1970's was centered near Le Hardy Rapids, between two resurgent domes - sections of the caldera floor that had earlier been pushed upward and faulted. Such resurgent domes form when magma rises to shallow levels beneath a caldera and slowly reinflates a previously depleted magma reservoir, pushing the overlying caldera floor upward to form a dome. The pressure of the inflating magma reservoir may even force some of the molten rock to emerge at the surface as lava.

The fact that the uplift documented in the 1970's was centered within the caldera near the resurgent domes seemed to indicate that the magma reservoir was again exerting pressure upward. What could be causing this? Was new magma entering Yellowstone's enormous reservoir from below? Perhaps volcanic gas was escaping from the magma reservoir, percolating upward and causing the surface to bow upward? Perhaps some of Yellowstone's hot water had become trapped beneath the surface, exerting pressure on the caldera floor from below? New volcano-monitoring data soon forced scientists to think again about what was occurring beneath Yellowstone's active caldera.

\section{The ups and downs of the caldera's movements}

To learn more about the changing ground levels in the Yellowstone area, scientists conducted additional surveys across the eastern part of the caldera nearly every year from 1983 to 1998 . In the 1990's, new and revolutionary satellite-based methods for tracking the Earth's changing ground surface - the Global Positioning System (GPS) and Interferometric Synthetic Aperture Radar (InSAR) — were applied by University of Utah, USGS, and other scientists to assemble a more detailed picture of how and when the ground moves above Yellowstone's magma reservoir.

These new data reveal that Yellowstone is in nearly continuous but frequently changing movement - the floor of the caldera continued to rise until 1984, stopped rising during 1984-85, and then subsided for the next 10 years. Parts of the central caldera began rising again in 1995, but a more complex pattern of uplift and subsidence has prevailed since 2000. InSAR data show that between 1995 and 1997 a large area along the northwest rim of the Yellowstone Caldera, centered near Norris Geyser Basin, started to rise. The picture that emerges from all these data is of a dynamic system in which the caldera floor is in almost constant motion-episodes of uplift 


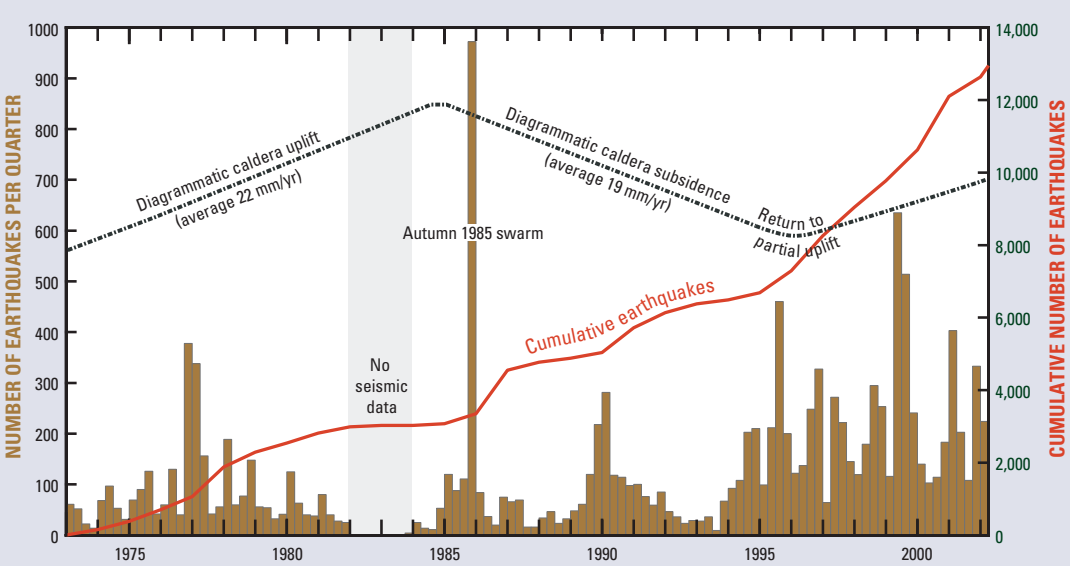

The Yellowstone area is one of the most seismically active parts of the United States, but the frequency of earthquakes varies dramatically and is related to other events in this active volcanic system. Precise measurements of elevation made regularly since the 1970's document the rise and fall (shown diagrammatically here) of the ground surface in the Yellowstone Caldera, thought to be caused by movements of magma (molten rock) or hydrothermal (hot, watery) fluids beneath the surface. The spectacular earthquake swarm of late 1985 may have been caused by the escape of hydrothermal fluids through the impermeable rock layer above the magma reservoir, which also initiated an episode of subsidence in the caldera.

and subsidence occur at various locations and over different time scales.

What could cause different areas in and around the caldera to go up and down over such short time intervals? A clue to this mystery, and a further indication that the region remains an active volcanic system, is the frequency and distribution of earthquakes at Yellowstone, one of the most seismically active areas in North America.

\section{Earthquakes at Yellowstone}

Thousands of small earthquakes rattle the Yellowstone region each year, and at least eight magnitude 6 or greater quakes have occurred in historical time. The largest was the magnitude 7.5 Hebgen Lake earthquake, which struck about 15 miles (24 km) northwest of the Yellowstone Caldera on August 18, 1959. That earthquake killed 28 people and caused damage of $\$ 11$ million (equivalent to $\$ 70$ million in 2003 dollars). The most recent large earthquake was a magnitude 6.1 shock inside the Yellowstone Caldera near Norris Geyser Basin on June 30, 1975.

An early written account of Yellowstone's earthquakes was given by Ferdinand Hayden in 1872 , when his survey party was camped on the northeast shore of Yellowstone Lake:

We were informed by mountain-men that these earthquake shocks are not uncommon, and at some seasons of the year very severe, and this fact is given by the Indians as the reason why they never visit that portion of the country. I have no doubt that if this part of the country should ever be settled and careful observations made, it will be found that earthquake shocks are of very common occurrence.
So common were these shocks at Yellowstone Lake that Hayden named this camp "Earthquake Camp," an apt name because the area remains one of the most common sites of earthquake swarms in the Yellowstone region.

To document and monitor this seismic activity, the USGS installed a permanent network of instruments in 1973. University of Utah and USGS scientists have since pinpointed the locations of thousands of earthquakes in the Yellowstone region. Most are small (magnitude less than 3), shallow quakes that sometimes occur in swarms lasting days to weeks or longer. Swarms have been located both within the caldera and between the caldera and the rupture zone of the Hebgen Lake earthquake to the northwest. Although many earthquakes are associated with known active faults or former sites of volcanic eruptions (vents), some are not.

\section{The migrating earthquake swarm of 1985}

The largest earthquake swarm recorded at Yellowstone since 1973 occurred just northwest of the caldera beginning in October 1985. Over the next several months, more than 3,000 earthquakes struck the upper Madison Valley area-more than 100 of them were felt near West Yellowstone, Montana. Previously, only about 100 total earthquake epicenters had been located in this area. During the 1985 swarm, as many as 100 to 200 events per day occurred from October 16 to 20, and the two largest events (magnitudes 4.9 and 4.3) struck on November 9.

A new analysis by University of Utah scientists of the 1985 swarm shows that during

\section{THE YELLOWSTONE VOLCANO OBSERVATORY}

Increased scientific surveillance of Yellowstone in the past 30 years has detected unmistakable changes in its vast underground volcanic system, similar to historical changes observed at many other large calderas (volcanic depressions) in the world. To strengthen the capabilities of scientists to track and respond to changes in Yellowstone's activity, a fifth U.S. volcano observatory was created in 2001, complementing existing ones for Hawaii, Alaska, the Cascades, and Long Valley, California. The Yellowstone Volcano Observatory (YVO) is supported jointly by the U.S. Geological Survey, the University of Utah, and Yellowstone National Park.

The principal goals of YVO include:

- Strengthen the monitoring system for tracking earthquake activity, uplift and subsidence, and changes in the hydrothermal (hot water) system;

- Assess the long-term potential hazards of volcanism, earthquakes, and explosive hydrothermal activity in the Yellowstone region;

- Enhance scientific understanding of active geologic and hydrologic processes occurring beneath Yellowstone and in the surrounding region of the Earth's crust; and

- Communicate new scientific results, the current status of Yellowstone's activity, and forecasts of potential hazardous hydrothermal explosions or volcanic eruptions to Yellowstone $\mathrm{Na}-$ tional Park staff, the public, and local, State, and Federal officials.

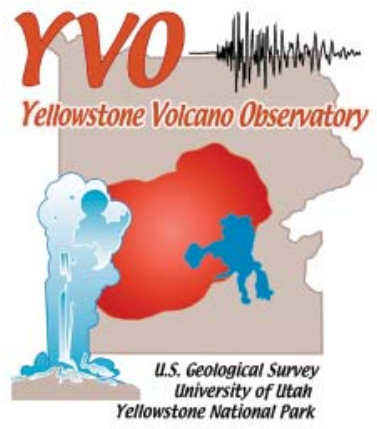




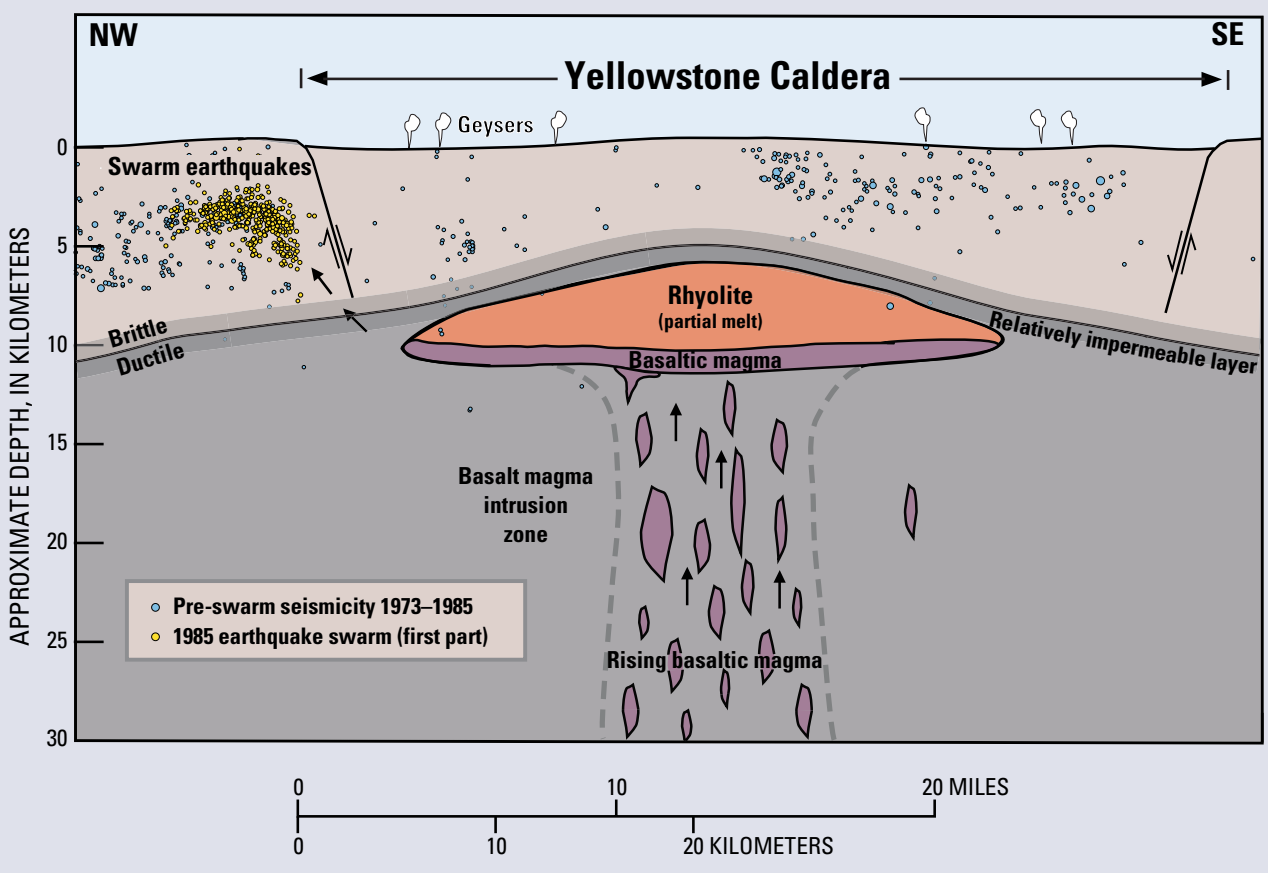

Volcanic and hydrothermal activity in the Yellowstone area is fueled by a large reservoir of magma (partially molten rock) beneath a caldera (volcanic depression) that formed in a cataclysmic eruption 640,000 years ago. The magma reservoir includes both rhyolitic magma, rich in silica $\left(\mathrm{SiO}_{2}\right)$, and basaltic magma, which contains less $\mathrm{SiO}_{2}$ and is denser. Capping the magma reservoir is a zone of hot, ductile rock that can slowly flow to close any fractures and is therefore relatively impermeable (meaning that fluids cannot easily pass through). The cooler rock above behaves in a more brittle manner and can be readily fractured. Sometimes the impermeable rock can be ruptured, allowing hot, salty fluids to escape upward and laterally, moving through cracks in brittle rock. As shown in this diagram, such a fluid release in 1985 is thought to have triggered a large swarm of earthquakes just northwest of the caldera.

the first month the locations of earthquakes moved to the northwest, away from the rim of the Yellowstone Caldera, along a narrow zone at an average rate of 500 feet $(150 \mathrm{~m})$ per day. For the rest of the swarm, into the following year, the earthquake locations grew systematically deeper, from less than 2 miles $(3 \mathrm{~km})$ to more than 5 miles $(8 \mathrm{~km})$ deep, at an average rate of about 80 feet $(25 \mathrm{~m})$ per day. This intense earthquake swarm generally coincided in time with the 1985-86 reversal of ground movement in the central part of the caldera-from uplift to subsidence. Was there a common trigger for both sets of events?

A likely cause of the 1985 earthquake swarm, according to scientists, was the rupture of a widespread layer of impermeable rock (through which fluids cannot pass) above the magma reservoir. The rupture of this rock layer allowed pressurized hydrothermal fluids (hot watery solutions) to move upward and laterally out of the caldera and into an adjacent network of fractures over a period of many weeks. As the fluids pushed through this network, cracks were opened and adjacent rocks were broken, resulting in several thousand small quakes. At the same time, according to this model, the lateral escape of fluids through the impermeable layer dramatically decreased the upward pressure normally exerted by the hydrothermal system beneath the caldera, resulting in subsidence there.

Another earthquake swarm occurred at Yellowstone in 1995. Because this swarm was not accompanied by caldera subsid- ence but rather by the latest period of caldera uplift, it has led scientists to ponder other possible models that link magma intrusion, hydrothermal fluid migration, and uplift of the caldera.

\section{Monitoring future activity}

The Yellowstone Volcano Observatory (YVO), by facilitating collaboration among Earth scientists and focusing scientific attention on the active geologic processes in Yellowstone, aims to increase our ability to forecast potential consequences of these processes. Those future consequences could be large destructive earthquakes, hydrothermal explosions, or volcanic eruptions. Forecasting whether hot pressurized fluids or even molten rock moving beneath Yellowstone will erupt at the surface depends on the ability of scientists to detect the changing activity by real-time monitoring and on understanding how the vast Yellowstone volcanic system, and other similar systems, work and behave. An ever-improving monitoring system will undoubtedly contribute to this understanding and reveal new aspects of Yellowstone's underground volcanic system.

Future monitoring at Yellowstone will seek answers to questions such as these:

- Is ground deformation caused by rising magma or by increased fluid pressure within the hydrothermal system?

- How are changes to the magma reservoir linked to and reflected in the overlying hydrothermal system?
- How can the underground migration of liquids and gases be detected? What changes does such activity produce in the hydrothermal fluids that emerge at the surface?

Coordination of scientists' efforts by the Yellowstone Volcanic Observatory will lead to better understanding of the region's remarkable volcanic and hydrothermal system and ultimately to a greater ability to predict potentially hazardous events. This work at Yellowstone is only part of the ongoing efforts by the USGS Volcano Hazards Program to protect people's lives and property in all of the volcanic regions of the United States, including the Pacific Northwest, California, Alaska, and Hawaii.

Steven R. Brantley, Jacob B. Lowenstern, Robert L. Christiansen, Robert B. Smith, Henry Heasler, Greg Waite, and Charles Wicks

Edited by Peter H. Stauffer

Graphic design by Sara Boore and Susan Mayfield Banner design by Bobbie Myers

COOPERATING ORGANIZATIONS

Yellowstone National Park University of Utah

For more information contact:

U.S. Geological Survey (650) 329-5227

http://volcanoes.usgs.gov/yvo or

Yellowstone National Park http://www.nps.gov/yell/home.htm

This Fact Sheet and any updates to it are available online at http://pubs.usgs.gov/fs/fs100-03/ 